\title{
ESTRESSE NO CUIDADO PERIOPERATÓRIO FRENTE AOS CONFLITOS ÉTICOS: ESTRATÉGIAS DE COPING
}

\author{
$\underline{\text { Ivanilza Carminha da Silva }^{1} \text {; }}$ Marluce Alves Nunes Oliveira ${ }^{2}$; Elaine Guedes Fontoura ${ }^{3}$
}

1- Graduanda de Enfermagem pela Universidade Estadual de Feira de Santana. Membro do Núcleo Interdisciplinar de Pesquisa e Estudos em Saúde - NIPES - UEFS. Bolsista PROBIC do Projeto de Pesquisa "Vivencias de conflitos e dilemas éticos na percepção da equipe enfermagem no centro cirúrgico". E-mail: nilzaisj@ hotmail.com Tel.: (75) 9145-8668.

2- Enfermeira. Doutora em Enfermagem. Professora do Curso de Enfermagem da Universidade Estadual de Feira de Santana. Membro do Núcleo Interdisciplinar de Pesquisa e Estudos em Saúde NIPES - UEFS. Coordenadora do Projeto de Pesquisa "Vivencias de conflitos e dilemas éticos na percepção da equipe enfermagem no centro cirúrgico". E-mail; milicialves@uefs.brTel: (75) $99972-$ 1457.

3- Enfermeira. Doutora em Enfermagem. Professora do Curso de Enfermagem da Universidade Estadual de Feira de Santana. Membro do Núcleo Interdisciplinar de Pesquisa e Estudos em Saúde NIPES - UEFS. Vice-Coordenadora do Projeto de Pesquisa "Vivencias de conflitos e dilemas éticos na percepção da equipe enfermagem no centro cirúrgico". E-mail: elaineguedesfont@uol.com.brTel: (75)99153-2730. 


\section{ESTRESSE NO CUIDADO PERIOPERATÓRIO FRENTE AOS CONFLITOS ÉTICOS: ESTRATÉGIAS DE COPING}

ÁREA TEMÁTICA: Produção do cuidado em Unidade Hospitalar.

INTRODUÇÃO: Os conflitos éticos que emergem no cuidado perioperatório, desencadeiam o estresse, vez que são recorrentes na ação da equipe de enfermagem. O centro cirúrgico por ser uma unidade de cuidados complexos, exige da equipe de enfermagem, capacidade para lidar com as demandas que surgem no cuidado perioperatório. Diante desse contexto, faz-se necessário que seja desenvolvido estratégias de coping a fim de favorecer o gerenciamento dessas situações. OBJETIVOS: conhecer os conflitos éticos vivenciados pela equipe de enfermagem que levam ao estresse no cuidado perioperatório e apontar estratégias de coping para sua prevenção. METODOLOGIA: Pesquisa inserida no projeto, "Vivências de conflitos e dilemas éticos na percepção da equipe enfermagem no centro cirúrgico", submetido ao Comitê de Ética em Pesquisa da Universidade Estadual de Feira de Santana, com aprovação CAAE $n^{\circ}$ 28656214.9.0000.0053. Trata-se de uma pesquisa de caráter qualitativo, realizada com oito profissionais da equipe de enfermagem que atuam no centro cirúrgico, há mais de um ano e que estavam em plena atividade laboral. As informações foram coletadas nos meses de novembro e dezembro de 2017 , por meio de entrevista semiestruturada, em uma unidade de centro cirúrgico de um hospital geral público, de grande porte, no município de Feira de Santana-BA. Foram duas questões norteadoras: Quais são as situações vivenciadas no perioperatório geradoras de estresse? Que cuidados a equipe de enfermagem deve ter para prevenção de conflitos éticos que geram estresse no perioperatório? Após a análise dos relatos emergiram duas categorias empíricas "Conflitos éticos vivenciados pela equipe de enfermagem que levam ao estresse no cuidado perioperatório" e "Estratégias de coping utilizadas pela equipe de enfermagem frente aos conflitos éticos que levam ao estresse no cuidado perioperatório. Para a concretização do processo de análise foi utilizado no primeiro momento a análise de conteúdo de Bardin e no segundo momento o Método de Análise de Problemas Morais, proposto por Diego Gracia. RESULTADOS: As situações de conflitos éticos que levam a equipe de enfermagem a vivenciar o estresse estão relacionadas a falta de recursos humanos e materiais; número insuficiente de salas de cirurgias e de leitos nas unidades de internação; e dificuldades de relacionamento interpessoal. Frente a estas demandas os profissionais destacaram estratégias de coping que ajudaram reduzir ou prevenir o estresse em centro cirúrgico, tais como: capacidade de resiliência, bom relacionamento interpessoal, diálogo, compromisso, dedicação ao trabalho, capacitação da equipe multiprofissional, o respeito e o trabalho em equipe. CONCLUSÃO: Percebemos que a equipe de enfermagem, vivencia conflitos éticos no cuidado perioperatório levando ao estresse. Faz-se necessário que a equipe de enfermagem esteja capacitada, a fim de desenvolver a autonomia para gerenciar os conflitos éticos e o estresse que surgem no cuidado no perioperatório. CONTRIBUIÇÕES: O estudo possibilita a equipe de enfermagem conhecer os conflitos éticos que geram estresse no perioperatório, estimula a desenvolver estratégias de coping, favorecendo o seu gerenciamento com autonomia e ética profissional.

PALAVRAS-CHAVE: Conflito; Cuidado perioperatório; Estresse. 


\section{REFERÊNCIAS:}

BARDIN, L. Análise de conteúdo. Edições 70; Lisboa- Portugal: 2011.

BEAUCHAMP, T. L.; CHILDRESS, J. F. Princípios da ética biomédica. São Paulo:

Loyola, p. 574, 2002.

BRASIL. Ministério da Saúde. Resolução CNS 466/12. Conselho Nacional de Saúde.

Comissão Nacional de Ética e Pesquisa com Seres Humanos. 2012.

CHRISTOFORO, B. E. B.; CARVALHO, D.S. Cuidados de enfermagem realizados ao

paciente cirúrgico no período pré-operatório. Rev. esc. enferm. USP , vol.43, n.1, p.14-22. 2009.

BRANDÃO, D. E. C; GALVÃO, C. M. Estresse da equipe de enfermagem que atua no período perioperatório: revisão integrativa. Rev Rene.; v. 14, n. 4, p. 836-44. 2013. DOI: http://dx.doi.org/10.15253/rev\%20rene.v14i4.3557. Acesso em: 06 jul. 2018.

FERREIRA DA FONSECA, J., SIQUEIRA COSTA, A., SEIXAS COUTINHO, D., DA COSTA GATO, R. Estratégias de coping em trabalhadores de enfermagem de um hospital universitário. Revista da Rede de Enfermagem do Nordeste, v. 16, n. 5, p. 656-663, 2015. DARYA, S. ; SHIVA, S. ; LADAN, F. M. The Effect of Emotion Regulation Training on Occupational Stress of Critical Care Nurses. Journal of Clinical and Diagnostic Research. v 10 (12), Dez; 2016. Disponível em:

<https://www.ncbi.nlm.nih.gov/pmc/articles/PMC5296554/pdf/jcdr-10-VC01.pdf>. Acesso em: 18 de março de 2018.

GOMES, A. V. B.; SILVA, M.C.F.; SOUZA P.F.J, BERZIN ,F.; NOGUEIRA, D.A.; ROSSI, W.C.J.; ESTEVES, A. Tratamento do estresse psicológico pela acupuntura, avaliado pela eletromiografia do músculo trapézio. Rev. dor. vol.13, n.3, p.220-224, 2012.

GRACIA, Diego. Procedimientos de decisión em ética clínica. Madrid: Editorial Triacastela, p. 157, 2007.

OLIVEIRA, M. A. N.; SANTA ROSA, D. O. Método de Análise de Problemas Morais aplicado à prática da Enfermagem. Feira de Santana: UEFS Editora, 2014. 184p.

SCHMIDTI, D. R.C. Modelo Demanda-Controle e estresse ocupacional entre profissionais de enfermagem: revisão integrativa. Rev. Bras. Enferm. v. 66, n. 5, p. 779-88, set-out; 2013. SILVA A. C. O. C.; OLIVEIRA M, A, N.; FONTOURA E, G.; SILVA I, C.; ASSIS T, A, V, A, O.; PEREIRA V, T.; MOITINHO M, M, C. Dilemas éticos vivenciados na prática dos enfermeiros no centro cirúrgico. In: Congresso Online - Gestão, Educação e Promoção da Saúde,V, 2016, São Paulo, processo de cuidar em saúde e doença( Anais) CONVIBRA. Disponível em: <http://www.convibra.com.br/upload/paper/2016/70/2016_70_12981.pdf〉. Acesso em: 18 de março de 2018.

SOUSA, S. M.; et al . Cuidado integral: desafio na atuação do enfermeiro. Rev. Bras.

Enferm. Brasília, v. 70, n. 3, p. 504-510, June 2017 . Available from

$<$ http://www.scielo.br/scielo.php?script=sci_arttext\&pid=S0034-

$71672017000300504 \& \operatorname{lng}=$ en\&nrm=iso>. access on 06 Aug. 2018. http://dx.doi.org/10.1590/0034-7167-2016-0380

VIEIRA, A. A.; OLIVEIRA, C. T. F. Resiliência no trabalho: uma análise comparativa entre as teorias funcionalista e crítica. Cad. EBAPE.BR. Rio de Janeiro, v. 15, n. spe, p. 409-427, Sept. 2017. Available from $<$ http://www.scielo.br/scielo.php?script=sci_arttext\&pid=S167939512017000700409\&lng=en\&nrm=iso>. access on 05 Aug. 2018.

http://dx.doi.org/10.1590/1679-395159496. 